\title{
Event review: Thematic Symposium Contributions of Technological Approaches to the Pre-history of South America: Theoretical Perspectives and Case Studies, Goiânia (Brazil)
}

\author{
Juliana de Resende Machado \\ Université Paris Ouest Nanterre La Défense. 21, allée de l’Úniversité 92023, Nanterre, France. \\ Email: ju.drmachado@hotmail.com
}

The thematic symposium "Contributions of technological approaches to the pre-history of South America: Theoretical perspectives and case studies" took place in Goiânia, Brazil, during the 8th Congress of the Brazilian Archaeological Society (XVIII Congresso da Sociedade de Arqueologia Brasileira), on 1 October 2015. The organizers, Dr. Maria Jacqueline Rodet (Lithic Technology Laboratory, Federal University of Minas Gerais) and Barbara Romina Sacur Silvestre (National Institute of Anthropology and Latin-American Thought, Buenos Aires University) had the goal of connecting specialists in South-American technological analyses, irrespective of the nature of the supporting material or the archaeological period.

There were a total of six papers, most concentrating on lithic remains. Within the few hours of the symposium, overviews of the pre-history of several periods and regions were presented, including their technological specificities and particular challenges. Potential solutions and advances achieved through the technological analysis of each context were also presented.

The presentation by João Carlos Moreno de Sousa kicked off the event with a theoretical discussion on the possibilities and limitations of technological analyses, especially when investigating modern hominin cognition through lithic industries.

The two following papers dealt with the lithic industries of pre-ceramic groups. Alex Sandro Alves de Barros added to the Brazilian archaeological map the Paranaíba River valley (eastern part of Minas Gerais state) demonstrating that the production of plano-convex implements persisted from the mid-Holocene, until the appearance of ceramics. Luis Felipe Bassi Alves detailed quartz-crystal knapping methods, showing the exploitation possibilities of this raw material, and how it was used by the groups that frequented the Jequitaí River basin, in the north of Minas Gerais state.

Working on the late archaeological period, Juliana de Resende Machado, presented research on surface lithic collections from a site in the São Francisco River valley (western part of the state of Bahia), showing how analysis of production technology and taphonomy ISSN: 2055-0472. URL: http://journals.ed.ac.uk/lithicstudies/ 
can be used to differentiate industries related to ceramic groups from older remains when they co-occur in the same collection samples.

The final two papers focused on ceramic remains. From the Paranaíba River valley, Wagner Magalhães presented the different production methods and firing techniques for vessels present in pre- and post-contact archaeological strata, and the influence of neoBrazilian society on the latter. Bringing the research presentations to a close, Rosiclér Theodoro da Silva and Daniela Dias Ortega's study of a pre-contact village in the Araguaia River basin questioned the homogeneity of the Uru ceramic tradition when it comes to ceramic paste preparation. They identified the presence of cauixi within the material; in this context a rarely-found non-plastic temper traditionally related to Amazonian cultures.

After the symposium, the participants were invited to turn their presentations into articles. Some are now part of the thematic issue on archaeology in the journal Teoria e Sociedade (UFMG), published in December 2015 and available online (http://www.fafich.ufmg.br/revistasociedade/index.php/rts/issue/view/16).

The mix of geographic regions, archaeological periods and materials was an interesting aspect of this thematic symposium because it improved dialogue between specialists who normally were isolated from each other. The same dynamism is expected for futures meetings but including more archaeologist from other nationalities. Discourse between researchers will continue at future South-American scientific events, particularly the next Congreso Internacional de Arqueología de la Cuenca del Plata in 2017, keeping with the intent of publicizing technological studies, especially lithic studies, and intensifying collaboration between South-American specialists. 